$\eta^{\prime}$

ANL-AFP-13

ANL-AFP-13

\title{
PRESSURE DROP AND VOLUME FRACTION OF GRID AND WIRE SPACED SUBASSEMBLIES
}

\author{
by \\ J. F. de Paz \\ Components Technology Division
}

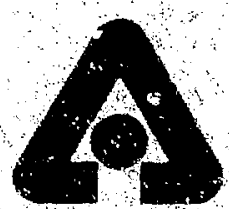

uederiustad

ARGONNE NATIONAL LABORATORY, ARGONNE, ILLINOIS

Prepared for the U. S. ENERGY RESEARCH AND DEVELOPMENT ADMINISTRATION MASTER under Contract W-31-109-Eng-38 
Distribution Category:

LMFBR Fuels and Materials Engineering and Development (UC-79b)

\section{Argonne National Laboratory 9700 South Cass Avenue Argonne, 11linois 60439}

PRESSURE DROP AND VOLUME FRACTION OF GRID AND WIRE SPACED SUBASSEMBLIES

by

\author{
J. F. de Paz \\ Components Technology Division
}

The ieport worice

Thus report was prepered as an axcount of work the Unsured by the United Suter Cavernment Nettice the United Stales nor the Unuted Sutes Energy
Rewarh and Derelopment Admutimition, not any of
thes sibcontractors. not any of thets contractors. warranty. exprels of thed employeer. makes any

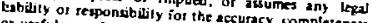
or usefulnes of any information, apparilu, product of

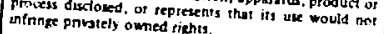


TABLE OF CONTENTS

Page

ABSTRACT. . . . .................... 1

z. INTRODUCTION ........................... 1

II. PRESSURE DROP, . . . . . . , , , , , , , , , 4

III. COMFARISON OF VARIOUS PRESSURE DROP CORRELATIONS FOR GRIDS . 8

IV. VOLUME FRACTIONS . . . . . . . . . . . . . . . . . .

v. CONCLUSIONS. . . . . . . . . . . . . . 16

REFERENCES. . . . . . . . . . . . . . . . . 17

ACKNOWLEDGMENT. . . . . . . . . . . . . . . . 18 


\section{LIST OF TABLES}

\section{Page}

I. Comparison of Pressure Drop in Grid Spacer Predicted

by Different Correlations. . . . . . . . . . . . . 10 


\section{L.IST OF PICURES}

Page

1. Honeycamb arld .................... 3

2. Subassembly Pressure Drop. . . . . . . . . . . . 6

3. Error Bands of Subnssembly Pressure Dropt. . . . . . . 7

4. Spacer volume Fraction in the core........... 13

5. Spacer Volume Fraction in the Axlal Blanket. ....... If

6. Fuel Volume Fraction................. 15 
Pressure Drod and Volume rraction of

Grid and Wire Spaced Subassemblies

\author{
J. F. de Paz
}

\begin{abstract}
The results of parametric calculations of pressure drop and volume fractions for honeycomb grid spaced fuel rod bundles are given, and a comparison with those of spizal wire spaced subassemblies is presented. The study covered the range of pin diaraeters from 0.3 to 0.45 inches, with linear heat ratings between 10 and $40 \mathrm{~kW} / \mathrm{ft}$. Included is also a brief discussion of the pressure drop pradtctions by several commonly used correlations.
\end{abstract}

\title{
I. Ineroduceion
}

The different spacer systems used in fuel rod burdles can be classiried into two groups: Longltudinal spacers attached to each fuel pin (such as fins or wites) and spacers attached to the subassembly duct at a number of axial planes (such as grids of various types). In order to evaluate the sultablity of elther concept, i study was made of the performance of one typical design in each class, natnely honeycomb grid and spiral wire. It must be emphastzed that any extension of the conclusions derived from this study to orher geometries in either of the above two classes can only be, at best, qualitative, as will be shown below. It was felt, however, that the study of two typical. spacer systems would be valuable as an indication of what can be achieved with either wires or grids. 
The study covered a range of pin diameters from 0.3 to 0.45 inches, and linear heat ratings of 10 to $40 \mathrm{~kW} / \mathrm{ft}$. The following parameters were kent constant in the calculations:

$\begin{array}{lc}\text { Total Power } & 500 \mathrm{MWt} \\ \text { Power in Core } & 90 \% \\ \text { Power in Axial Blanket } & 8 \% \\ \text { Power in Radial Blanket } & 2 \% \\ \text { Radial Power Peaking Factor } & 1.375 \\ \text { Axial Power Peaking Factor } & 1.200 \\ \text { Maximum Sodium Velocity } & 25 \mathrm{ft} / \mathrm{sec} \\ \text { Temperature Rise Across Core } & 300^{\circ} \mathrm{F} \\ \text { Sodium Outlet Temperature } & 1050^{\circ} \mathrm{F} \\ \text { Active Core Height } & 36 \mathrm{in} . \\ \text { Axial Blanket Thickness } & 15 \mathrm{in} . \\ \text { Axial Reflector Thickness } & 5 \mathrm{in} . \\ \text { Plenum Length } & 30 \mathrm{in} . \\ \text { Pellet Density } & 95 \% \\ \text { Number of Pins Per Assembly } & 169 \\ \text { Number oi Control Rod Positions } & 36\end{array}$

These values were chosen so as to ensure applicability of the resulting data to the reference cores considered in the ongoing optimization studies. ${ }^{1}$

The grids under consideration were of the Westinghouse honeycomb design described in Ref. I and shown in Fig. 1. The characteristic dimensions of the grid and suppor: straps were taken to be 0.016 and 2.25 inches for the support strap thickness $\left(t_{s}\right)$ and height $\left(H_{s}\right)$ and 0.009 and $0.55 \mathrm{jnches}$ for the grid strap thickness $\left(t_{g}\right)$ and helght $\left(\mathrm{H}_{\mathrm{g}}\right)$ respectively. These values were recommended by Bef. 2 on the basis of in-pile experience, and were maintained constant in the calculations. With honeycomb grids, the fuel elements are kept in position by elastic dimples stamped into the grid straps. There is, of course, a limit to the dimple size that can be achieved for a given design. This limit is a function of the grid geometry and was given by Ref. 3 as $0.1 \mathrm{in.}$ for the above grid dimensions. The rod diameters and spacings considered in this study required dimple sizes which were always smaller than this limit. 


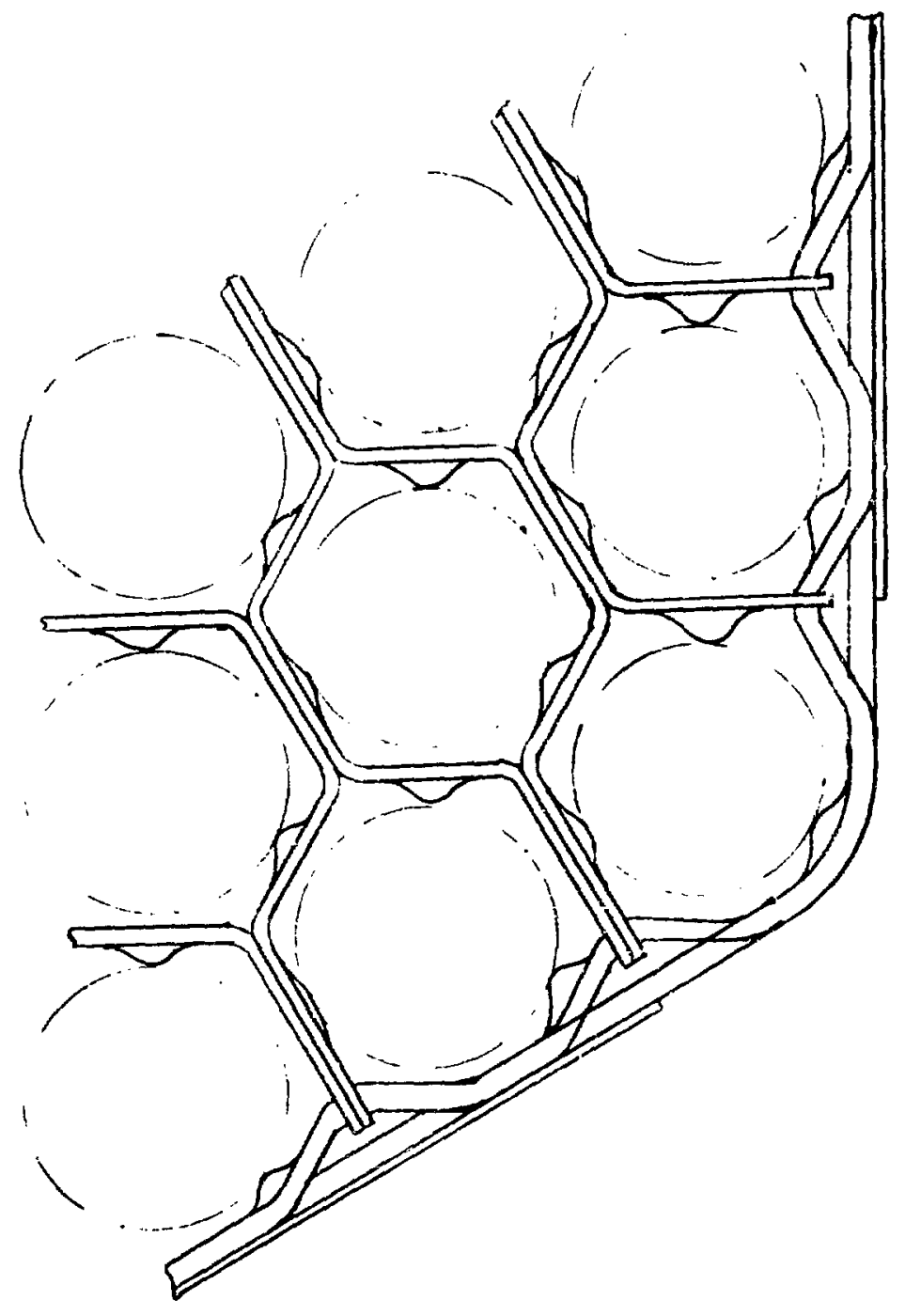

Fig. 1. Honeycomb Grid (From Reference 2) 


\section{Pressure Drop}

The pressure drop In the grld spited subasisemblles is computed by adding the pressure drop in the grids

$$
N\left(K+\frac{f_{g}^{L} g}{D_{g}}\right) \frac{\mathrm{th}^{2}}{2 \rho \mathrm{A}_{g}^{2}}
$$

to that of the bare rod sections

$$
\frac{f_{0} L_{0}}{D_{0}} \frac{\dot{m}^{2}}{2 p A_{0}^{2}}
$$

where $f$ designates friction coefficient, $L$ length, $D$ equivalent diameter, $A$ area and $\dot{m}$ the mass flow rate. The sublndices $g$ and o correspond to the grid and bare rod sections, respectively, and $N$ is the number of grids. The above expression (1) for the pressure drop in the grids is seen to consist of a first term accounting for the form loss in the abrupt section changes, and a second term, proportional to the grid iength $L_{g}$, corresponding to the friction losses. The friction coefficients werc conputed using standard correlations for turbulent flow in pipes (of the form $f=0.316 / \mathrm{Re}^{0.25}$ ). The energy loss coefficlent was given by Ref. 3 as

$$
K=0.75\left(1-\frac{A_{g}}{A_{0}}\right)+\left(1-\frac{A_{g}}{A_{0}}\right)^{2}
$$

and the grid flow area:

$$
A_{g}=A_{0}-t_{g}(H-0.032) 2 \sqrt{3}-\frac{t_{g}^{F}}{\sqrt{3}}\left(12 n^{2}-20 n-13\right)
$$

where $P$ is the rod pitch, $n$ tive number of rows of rods (counting the center rod as row one), and $H$ the distance between inside flats of the hex can. The value of the latier required for a given rod diameter $D$ and pitch is

$$
H=(2 n-2) P \cos 30^{\circ}+2\left[0.567 D+t_{s}+0.016\right]
$$


The pressure drop given by Eqs. (1), (2) and (3) were compared with that occurring in wire spaced subassemblies of the same rod diameter and linear heat rating, and assuning no clearance in the rod bundle. The latter pressure drop was computed, following the approach of reference 4, by distributing the subassembly fluw amongst the inner and outer channels according to their equivalent diameters and flow areas, and taking into account the effect of the wire spacer by means of a factor $M$ applied to the standard expression for the pressure drop in a uniform duct. This factor is a function of the Raynolds number, bundle pltch to diameter ratio $P / D$, and wire pitch to rod diameter ratio H/D:

$$
M=\frac{1.034}{(P / D)^{0.124}}+\frac{29.7(P / D)^{6.94} \mathrm{Re}^{0.086}}{(H / D)^{2.239}}{ }^{0.885}
$$

The results are presented in Figs. 2 and 3 . It is seen in Fig. 2 that the pressure drop in gridded assemblies decreases more rapidly with increasIng linear heat rating than that of wire spaced assemblies, resulting in pressure drops that become significantly lower when the linear heat rate is higher than approximately $20 \mathrm{~kW} / \mathrm{ft}$, for the range of pin diameters under consideration. It should be noted, however, that there is a considerable degree of uncertainty in the actual values of pressure drop; name $1 y, \pm 14 \%$ for the wire spaced rod bundles according to Ref. 4, and $\pm 15 \%$ for gridded assemblies of less than 217 pins, according to Ref. 5. Figure 3 shows the uncertainty bancis for pressure drops for the $0.4 \mathrm{in}$. pins as a function of the linear heat rating. It is seen that, while there is a significant difference in the nominal pressure drop for gridded and wire-wrapped assemblies at high linear heat rates, the crossover cannot be accurately established. In fact, for linear heat rates lower than $20 \mathrm{kN} / \mathrm{ft}$ there seems to be no significant difference in the performance of either type of spacer, as regards pressure drop. 


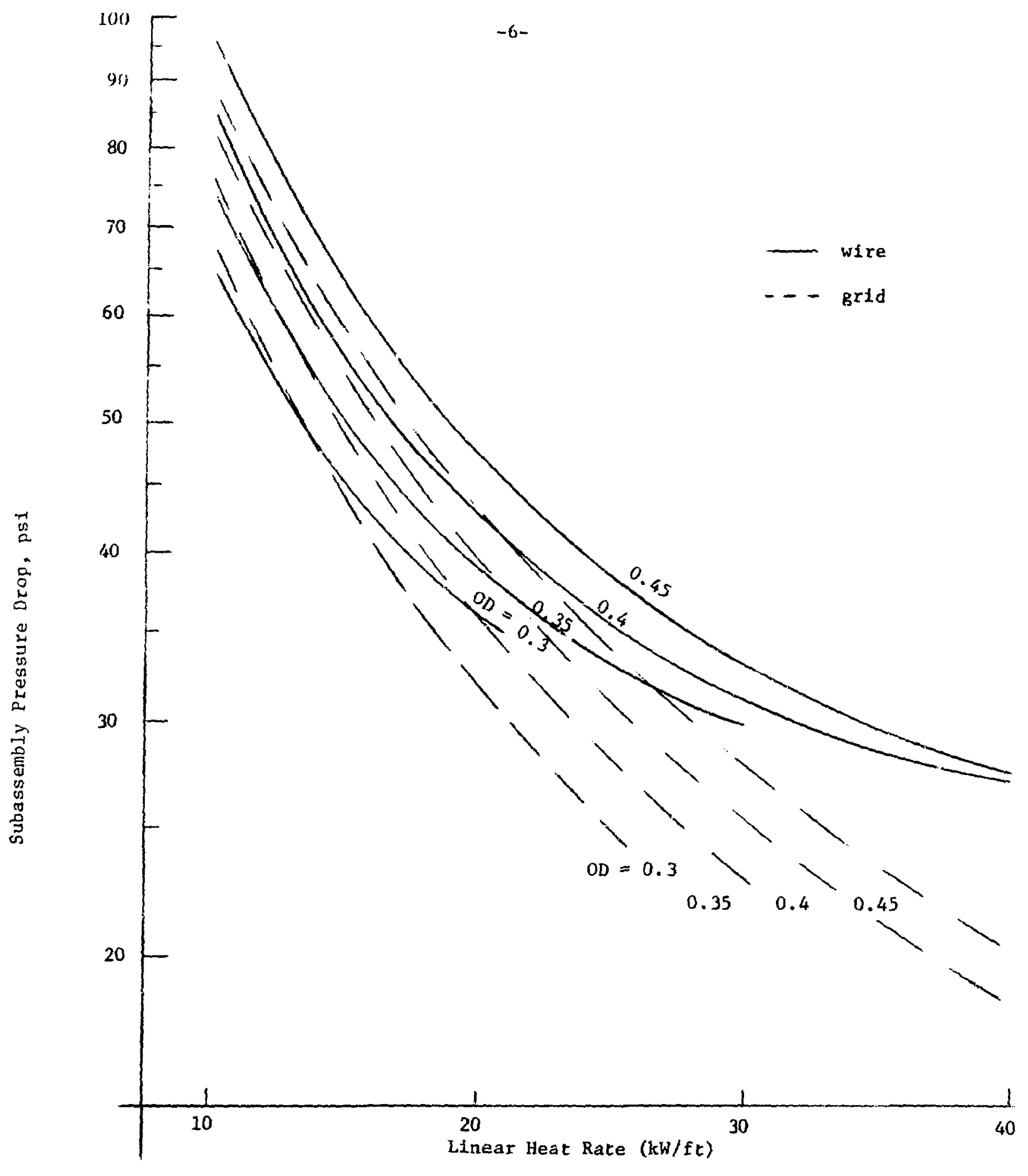

Fig. 2. Subassembly Pressure Drop 


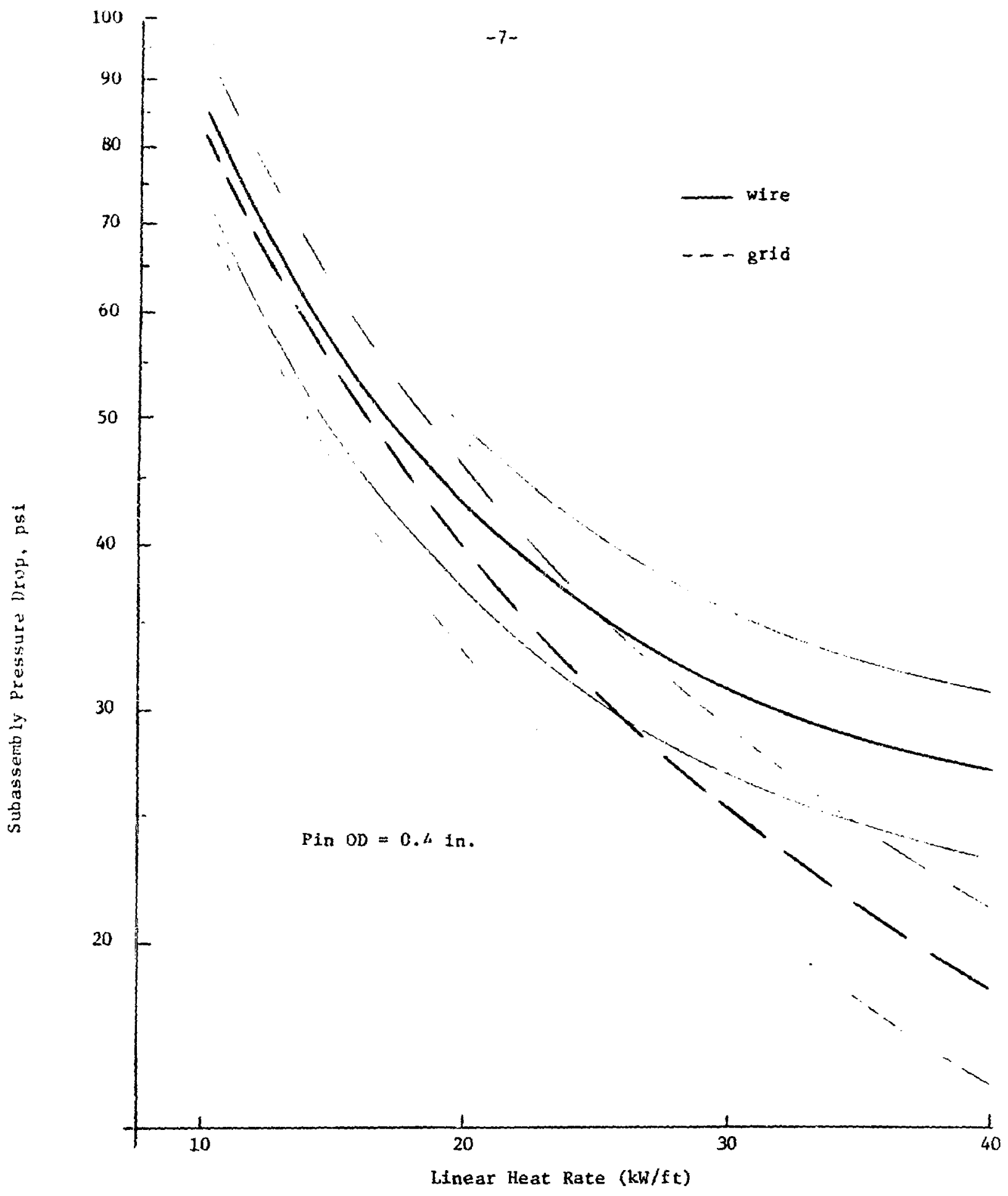

F18. 3. Error Bands of Subassembly Pressure Drops 


\section{Comparison of Various Pressure Drop Correlations for Grids}

In the following, the correlation for the pressure drop in the grid spacer given by expression (1) and equation (3) will be compared, with the results of past studies. The second term in the right hand side of (3) is commonly used to account for the pressure drop in an abrupt expansion, while the first term, which was obtained by Westinghouse from experimental data on their honeycomb grids, agrees quite we1l. with the values presented in Reference 6 for the loss coefficient in a sudden contraction when $A_{g} / A_{0}>0.7$ with Re $>10^{4}$. C. Betts, et a1. (Ref. 9) compute the pressure drop across grids using a different loss coefficient for the sudden contraction, namely $0.5\left(1-A_{g} / A_{0}\right)$. Their predictions are approximately $16 \%$ lower than their experimental data, whereas using WARD's coefficient of $0.75\left(1-A_{g} / A_{0}\right)$ results in computed values of the pressure drop which are approximately $3 \%$ higher than Bett's data. This seems to confirm also the validity of Eq. (3). The value of $\mathrm{K}$, which describes the form losses, was found in the present study to be equally important in terms of magnitude to that of the ratio $\mathrm{f}_{\mathrm{g}} \mathrm{L}_{\mathrm{g}} / \mathrm{D}_{\mathrm{g}}$, which is proportional to the friction losses, contrary to the postulations of Ref. 7 , where the friction loss is said to be small compared with the form loss. Since the friction losses are proportional to grid length, the total spacer losses would be expected to depend signiflcantly on the latter.

A different approach is followed by de Stordeur ${ }^{7}$ and Rehme. ${ }^{8}$ Instead of computing separately the form and friction losses, they express the grid pressure drop $\Delta \mathrm{P}_{\mathrm{g}}$ in terms of an overall spacer drag coefficient. Thus reference 7 gives: 


$$
\Delta P_{g}=C_{s} \frac{\dot{m}^{\prime}}{2 p A_{g}^{2}} \frac{\Lambda_{0}-A_{g}}{A_{o}}
$$

where $C_{s}$ was determined experimentally as a function of Reynolds number and found to be dependent on the type of grid (honeycomb or line-of-sight) but equal for all the different honeycomb grids considered. $C_{s}$ was also seen to be approximately equal to 1.65 for $\operatorname{Re}>4 \times 10^{4}$. Rehme ${ }^{8}$ pistulates:

$$
\Delta P_{g}=C_{v} \frac{\dot{m}^{2}}{2 p A_{0}^{2}}\left(\frac{A_{0}-A_{g}}{A_{0}}\right)^{2}
$$

Again $\mathrm{C}_{\mathrm{v}}$ was found to be almost constant for large Reynolds numbers, tendIng to a value of $2,6.5$. Furthermore the same value of $C_{v}$ was seen to fit data from all the grid types studied (including both line-of-sight and honeycomb).

By equating the right-hand side of Eq. (4) with expression (1), a value of $\mathrm{C}_{s}$ is calculated as:

$$
C_{s}^{\prime}=0.75+\frac{A_{0}-A_{g}}{A_{0}}+\frac{A_{0}}{A_{0}-A_{g}} \times \frac{f_{g} L_{g}}{D_{g}}
$$

Likewise, equating (5) with (1) gives

$$
C_{v}^{\prime}=\left(\frac{A_{o}}{A_{g}}\right)^{2}\left[0.75 \frac{A_{0}}{A_{0}-A_{g}}+1+\left(\frac{A_{0}}{A_{0}-A_{g}}\right)^{2} \frac{f_{g} L_{g}}{D_{g}}\right]
$$

The values of $C_{s}^{\prime}$ computed in this way for Reynolds numbers between $0.4 \times 10^{5}$ and $0.8 \times 10^{5}$, were found to range between 1.7 and 2.14 , fairly close to the measured value of $\sim 1.7$, while $C_{v}^{\prime}$ ranged between 15.7 and 17.8 ; since the value of $C_{v}$ measured by Rehme is only 26.5 , his correlation results in pressure loss predictions considerably lower than those of expression (1). Table I shows the values of pressure drop predicted by the three correlations for $0.35^{\prime \prime}$ pins and over a range of $\mathrm{P} / \mathrm{D}$ ratios (all other parameters as listed in section I). The WARD and de Stordeur correlations 
Table I. Comparison of Pressure Drop in Grid Spacer Predicted by Different Correlations. (Pin 0.D.: 0.35". Average Na velocity: $25 \mathrm{ft} / \mathrm{sec}$. Average temperature: $900^{\circ} \mathrm{F}$. Reynolds number based on the equivalent diameter and $\mathrm{Na}$ velocity at the grid.)

\begin{tabular}{lcccc}
\hline $\begin{array}{l}\text { P1tch } \\
\text { Diameter }\end{array}$ & $\operatorname{Re}$ & $\begin{array}{c}\text { WARD } \\
\text { (ref. 2) }\end{array}$ & $\begin{array}{c}\text { Pressure drop per grid (ps 1) } \\
\text { (ref. 7) }\end{array}$ & $\begin{array}{c}\text { Rehme } \\
\text { (ref. 8) }\end{array}$ \\
\cline { 2 - 5 } 1.097 & $0.4 \times 10^{5}$ & 2.9 & 2.2 & 1.3 \\
1.162 & $0.5 \times 10^{5}$ & 1.7 & 1.5 & 0.7 \\
1.224 & $0.7 \times 10^{5}$ & 1.1 & 1.0 & 0.4 \\
1.283 & $0.8 \times 10^{5}$ & 0.94 & 0.96 & 0.4 \\
\hline
\end{tabular}


agree quite well, particularly at high Reynolds numbers. Rehme's shows considerable discrepancy. A reason can be postulated for this which also explains the apparent contradiction of formulas (4) and (5), in which the pressure drop is given as independent of grid length, and expression (1), which is a function of $\mathrm{L}_{\mathrm{g}}$. While several honeycomb grids were included in de Stordeur's study, all the high Reynolds number data was taken on Westinghouse grids. It is possible that high Re data taken with other grids might have shown a dependence of $C_{s}$ with grid geometry (even within the honeycomb type). On the other hand tre honeycomb grids studies by Rehme had a length of $0.31 "$ (vs. $0.55^{\prime \prime}$ for the reference grids considered here). This shorter length might account for some of the difference found in the pressure drop, with other geometric dissimilarities also contributing to it. It is concluded from the above that the results provided by the pressure drop correlations must be viewed with caution and only qualitative conclusions drawn from them unless experimental data is available for the specific grid geometry being considered. This is particularly true of more general correlations, like (4) and (5), which do not allow for separate computation of the form and friction losses.

\section{Volume Fractions}

The spacer volume fractions in the gridded assemblies is determined by the volume of each grid, given by the expression

$$
t_{s}(H-0.032) 2 \sqrt{3} H_{s}+\frac{t_{g} P}{\sqrt{3}}\left(12 n^{2}-20 n-13\right) H_{g}
$$

and the number of grids, which is in turn a function of the grid spans. The vaiues recommended by Ref. 3 for the span of optimized grids (in inches) 
can be expressed as functions of pin diameter by linear equations:

$$
\begin{aligned}
& \text { core region span }=18.182 \times \mathrm{D}+3.773 \\
& \text { plenum and blanket regton span }=3.333 * \mathrm{D}+4.333 .
\end{aligned}
$$

The resulting volume fraction is compared with that of wire in Figs. 4 and 5. The wire volume fraction is seen to fncrease with heat rating since, for a given coolant velocity and temperature rise, a higher linear heat rate requires a larger flow area and distance between pins. On the other hand, the grid volume fraction is seen to decrease slightly with increasing power rating. This is due to the fact that the subassembly cross-sectional area increases linearly with heat rate, whereas, for a constant grid strap thickness and height, the grid volume increases only with the square root of the subassembly area. As a result, at high heat rates the spacer volume fraction is much smaller for grids than for wires. The grid volume fraction is seen to be smaller in the blarkets, due to the larger span allowable in that region.

The fuel volume fraction for either spacer concept, shown in Fig. 6, reflects the effect of duct thickness and intersubassembly gap, as well as that of the spacer volume fractions themselves. The duct thickness is determined by the subassembly pressure drop and flat-to-flat distance, and its value chosen so as to make the pressure induced stresses in the can equal to 1.5 times the maximum allowable stress intensity for the material under consideration* (20\% CW316SS in this study). To allow for the pressure drop downstream of the fuel rod bundle, an extra 30 psi has been added to the pressure losses shown in Fig. 2 when computing the duct thickness. The

\footnotetext{
*See Reference 1 for furthe: details.
} 
Spacer Volume Fraction in the Core (\%)

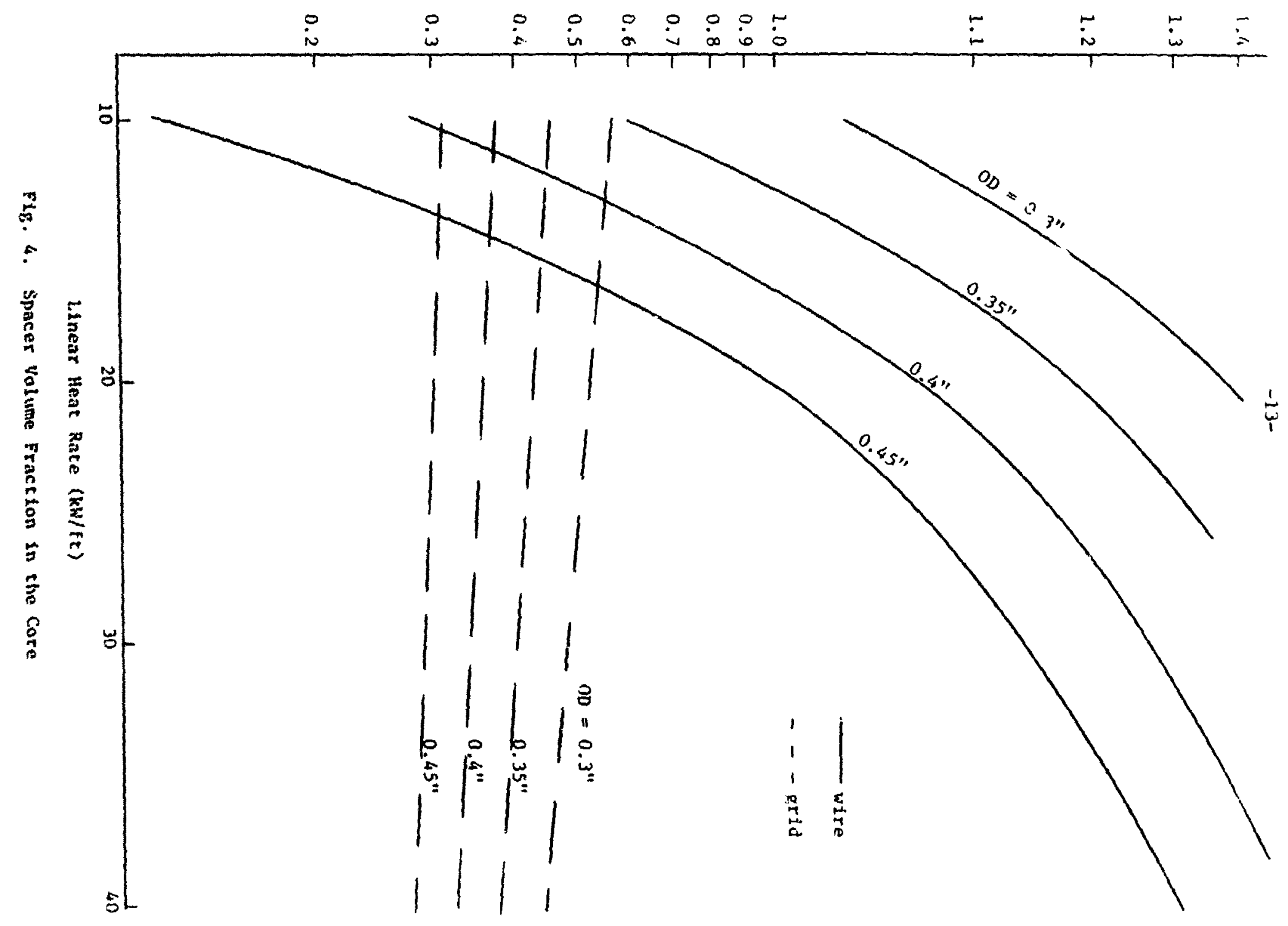


Spacer Volume Fraction in the Axial Blanket (\%)

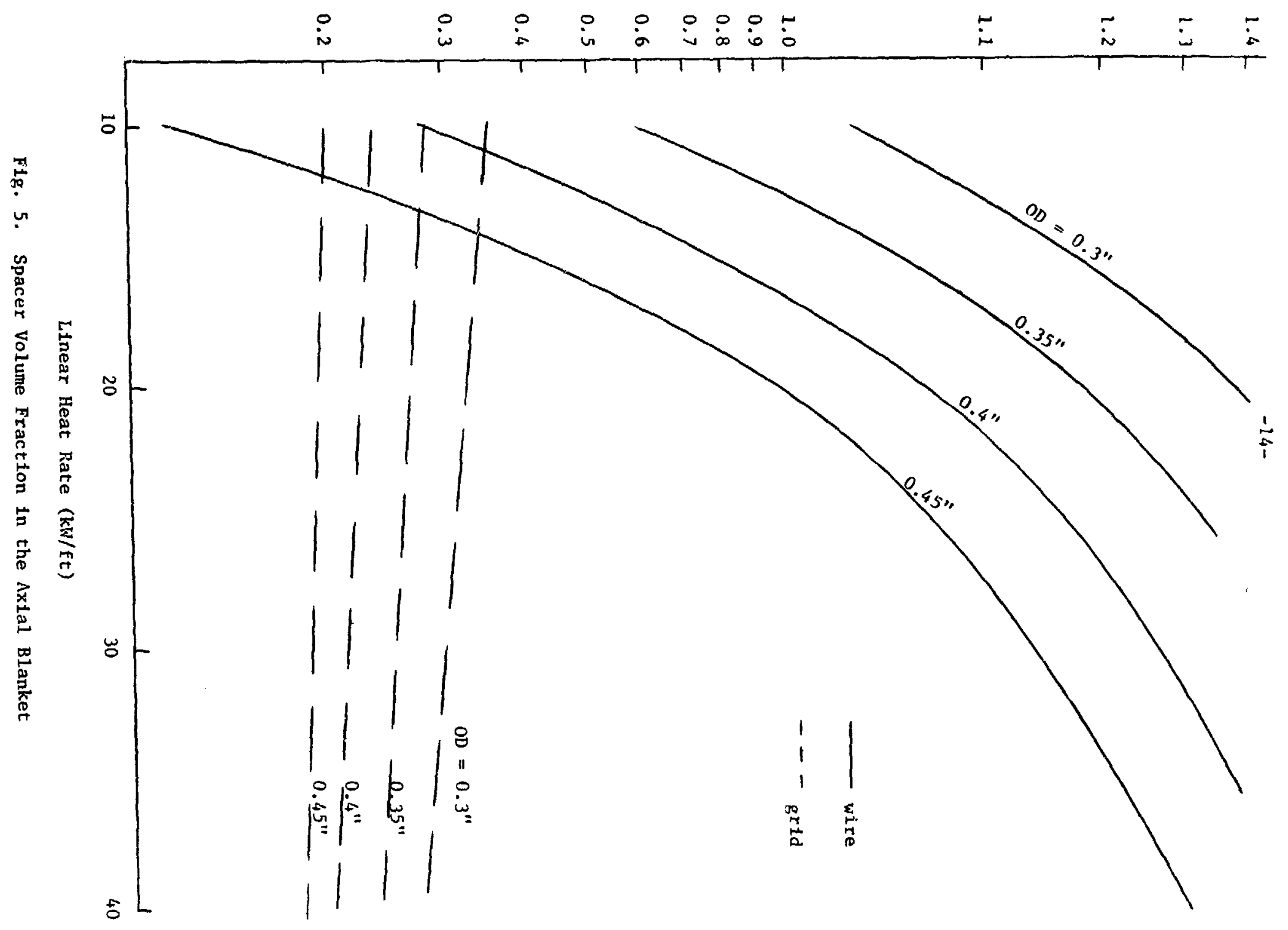


Fuel Volume fraction (\%)

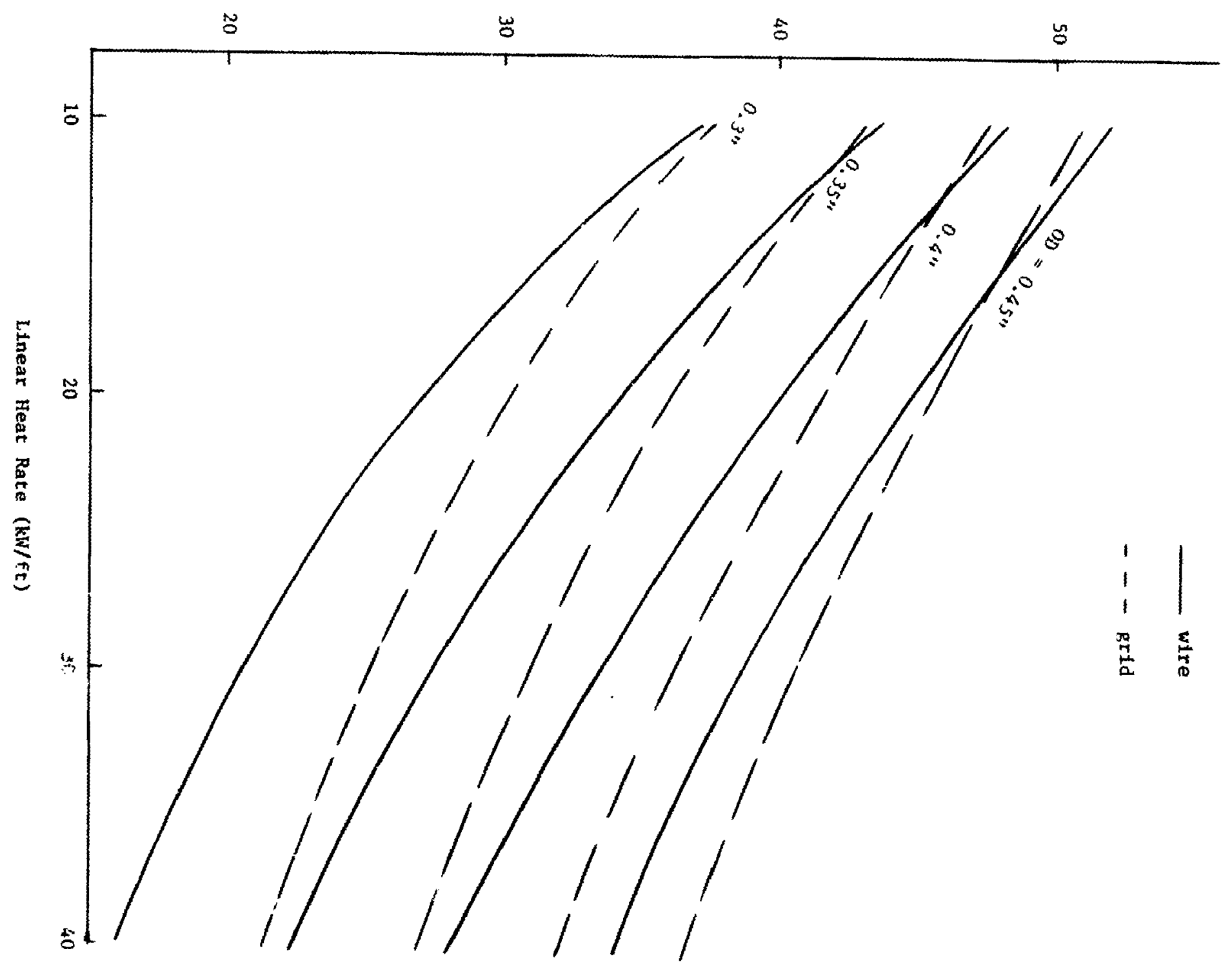


inter-subassembly gap has been assumed to be proportionil to the inside distance between flats and equal to, approximately, one twentieth of the latter.

\section{Conclusions}

The pressure drops occurring in grid spacers are strongly dependent on the grid geometry (grid strap thickness and helght, grid span, etc.). When using the grid dinensions recommended in Ref. 3, the pressure drop produced by honeycomb grid spaced subassemblies is smaller than that of wire spaced bundles for large linear heat ratings. For values of the latter smaller than approximately $20 \mathrm{~kW} / \mathrm{ft}$, the difference in the pressure drop produced by either spacer is small and cannot be computed accurately with the avallable correlations.

The spacer volume fraction for gridded assemblies is relatively insensitive to linear heat rate, while that of wire spacers increases considerable with power rating. As a result, for high values of the latter the grid spacers have volume fractions significantly lower than the spiral wires. The grid spacers result also in higher fuel volume fractions at high linear heat rates. 


\section{References}

i. W. P. Barthold, et al, "Breeding Performance and Pin Diameter Optimization for Mixed Carbide and Nitride Fuels in 5000 MWt LMFBRs," draft.

2. "11:1 Scale Rod Bundle Flow Tests," WARD-0X-3045-6, Westinghouse Advanced Reactors Division (February 1974).

3. A. Boltax, WARD, memorandum to W. P. Barthold (April 25, 1975).

4. E H. Novendstern, "Turbulent Flow Pressure Drop Model for Fuel Rod Assemblies Utilizing a Helical Wire-Wrap Spacer System," Nuclear Engineering and Design, Vol. 22 (1972).

5. A. L. Schwallie, WARD, personal communication.

6. J. G. Yevick and A. Amorosi, "Fast Reactor Technology: Plant Design," The M.I.T. Press, Cambridge, Mass., 1966.

7. A. N deSrordeur, "Drag Coefficients for Fuel Element Spacer;" Nucleonics 19(6), June 1961.

8. K. Rehme, "Pressure Drop Correlations for Fuel Element Spacers," Nuclear Technology 17, January 1973.

9. C. Betts, R. S. Capewell. W. R. Winn and H. F. Lunt, "DFR 77-PIn Subassembly Flow Evaluation," TRG Report 644 (R). UKAEA, 1963. 
Acknowledgment

The author is indebted to Dr. W. P. Barthold for several enlightening discussions of this work. 